\title{
The Contribution of Instructor, Peer and University Support for Promoting Psychological Well-Being among Students in the Amhara Regional Universities
}

Belay Tefera Kibret* and Gerum Tareke

Department of Psychology, School of Psychology, College of Education and Behavioral Studies, Addis Ababa, Ethiopia

\begin{abstract}
Success in higher education is most commonly indexed in Ethiopia with academic success despite the fact that the major factor undergirding this success appears to be non-academic in nature. The main intent of this study was to examine one of these academic profiles of university students (i.e., psychological wellbeing) and the extent to which it was affected by perceived (university, peer group and instructors) support services. Data were collected from a sample of 384 students (217 males and 167 females) drawn from three universities (Bahir Dar, Wollo, and Debre Tabor) in the Amhara Regional State. Structured questionnaire composed of various components originally developed by experts in the field was used for the present study; in fact after validating the sub scales. Findings indicated that psychological wellbeing general score, 'environmental mastery', 'purpose in life', and 'self-acceptance' were lower compared to autonomy, personal growth, and relationship with others. Female students and those from lower family income group were more vulnerable than their counterparts unlike grade level in which, contrary to previous research, little differences were noted in psychological well-being among students of different university grade levels. It was also found that university support, teacher support, and peer support were perceived to be lower. Yet, peer support and teacher support were found to be significant predictors of psychological well-being compared to university support that proved to be less useful. The results were discussed and recommendations were forwarded to fill in the gaps noted.
\end{abstract}

Keywords: University students; Peer support; University support; Teacher support; Psychological well-being

\section{Introduction}

College adjustment has been a point of concern among many students. Although college transitions can be difficult for many students, students do clearly vary greatly in their ability to cope with and adjust to challenges, and some students face far more challenges than others. For example, evidences suggest that meaning in one's life and deciding on a future career often have greater difficulty adjusting for students from lower socioeconomic backgrounds [1]. Those who adapt effectively to their new social and academic environment are much more likely to persist in college and ultimately earn a degree [2].

A potentially important resource for successfully accomplishing this life transition is positive psychological functioning, known as 'psychological well-being'. Psychological well-being is life imbued, on the one hand, with overall satisfaction, happiness and healthy state of mind [3] or life lived in a fully and deeply satisfying manner [4] and significantly devoid, on the other hand, of ailments, infirmities or illnesses [5]. Hence, people are inherently motivated towards and deploy resources for maintaining and displaying psychological well-being [6] that basically comprises self-acceptance, autonomy, environmental mastery, purpose in life, positive relations with others, and personal growth. The skills and perceptions that comprise psychological wellbeing are crucial for successfully engaging in meaningful relationships, navigating one's (physical, social, and acdemic) environment, and realizing one's fullest potential throughout the lifespan. In other words, psychological well-being is important not only for students making the transition to college, but also to those already in and also outside college environments.

A great deal of psychological research has explored the negative and positive sources of psychological well-being. These sources include one's overall wealth, health, income, and social support. More recently, researchers have rather come more interested in exploring such contextual factors of psychological wellness as institutional support, teacher support and peer support [7-9]. Findings indicate that these contextual factors are the building blocks of psychological wellness [79] or are variables that make up healthy habits and protect students from harm [10]. One study of a college student population demonstrated that lack of teacher and college support can have disastrous effects on students, families, and entire schools; thus negatively impacting on students' psychological well-being [10,11].

Universities (colleges) are important contexts of development because adolescents and youths spend much of their time at school in the companionship of teachers' [12]. These institutions can promote psychological wellbeing to the extent that they retain a healthy academic environment. Within a healthy environment, college classroom can become resilient communities that provide essential support and guidance so that vulnerable students can learn and succeed [13]. Wellness and school success are most likely when students learn in a safe, caring, and supportive environment [14]. The schools (colleges) that contribute to psychological wellness basically retain the characteristic feature of being perceived as relevant in terms of course programming, empowering to exercise control over what happens to

*Corresponding author: Kibret BT, Department of Psychology, School of Psychology, College of Education and Behavioral Studies, Addis Ababa, Ethiopia, Tel: +251111 225949; E-mail: belaytefera@yahoo.com

Received: June 19, 2017; Accepted: June 22, 2017; Published: June 292017

Citation: Kibret BT, Tareke G (2017) The Contribution of Instructor, Peer and University Support for Promoting Psychological Well-Being among Students in the Amhara Regional Universities. Clin Exp Psychol 3: 154. doi: 10.4172/24712701.1000154

Copyright: ( 2017 Kibret BT, et al. This is an open-access article distributed unde the terms of the Creative Commons Attribution License, which permits unrestricted use, distribution, and reproduction in any medium, provided the original author and source are credited. 
them at school, fair, firm, clear, and consistent in terms of disciplining policies and their enforcement, rational in the reward system, strong and effective school governance, administration and leadership, and ensuring a sense of belongingness and connectedness [15-17].

Oberle et al. [18] also found significant variability in life satisfaction due to the school contexts to which students belonged. The nature of school context as well as the relationships with teachers and students in school has been identified as critical factors in students' current and future well-being. School can be described as a work place of students, teachers and staff working in the school and strengthen social and cultural capita, especially among at-risk students [19]. According to Ahonen and Rijala [20] the students' plan for further education were closely related to the linking for school, which is known to be an indicator of subjective well-being.

One study displaying the person-environment interaction demonstrated that neither students' values nor the department they studied in directly affected their psychological wellness [21]. The interaction between the two, however, had a significant effect on psychological well-being. Positive teacher-student relationship have been defined as the degree to which students' feel respected, supported and valued by their teachers. Similarly, the student -teacher relationship is a critical aspect of the school environment, with studies demonstrating that student perception of positive relations with teachers and other school staff contribute to improved social and emotional functioning over time. Moreover, supportive student -teacher relationships are linked to beneficial social-emotional out comes, such as positive peer relations as well as decreases in suicidal ideations, externalizing behaviors, emotional distress, violence, substance abuse, and sexual activity [13]. Furthermore, supportive student-teacher relationships mitigate such negative academic outcomes as risk for school failure [13], school activity involvement improves well-being, GAP, environmental mastery and personal growth, and lowers school absenteeism, potential risks of delinquent behavior [22].

Peer group support is even a more promising social context and source of development, learning and psychological well-being [23] because individuals spend more time in peer groups [24]. Of course, peer support is one of the most important assets for students' well-being [14], promotes individual well-being and academic success [23], buffers against maladjustment, help adolescents build social skills and learn that others think and feel differently from the way they do [25], provide young people with approval and support in daily life, experiences of sharing and cooperating, standards for social comparison, opportunities to try out adult roles, leisure time reaction, and forums for personal and intimate disclosure of experiences, thoughts, and ideas; essential for the evolution of the cognitive-emotional development and good adjustment [25], contributed significantly to good psychological wellness [26], enhance happiness, coping with the stressors they are exposed to, counter act loneliness and isolation [27]. In contrast, negative experiences with others such as having conflict in relationships with friends are associated with a decrease in psychological well-being [28]. Similarly, peer rejection, loneliness, low self-worth and depression are frequently reported by children and adolescents who lack friends completely [23] and adolescents and youth could experience marked level of stress as a result of not having friends [27]. Peer support is so valued in Ethiopian higher education institutions that universities have adopted it as one pedagogical strategy in the PG and UG curricula, and instituted a form of cooperative learning called ' 1 to 5 students' team up approach' as an official student-support study approach to be monitored by the departments. Some universities have gone extra mile preparing a guideline as to how to implement it [29].
This being the case, several researchers haven't, nevertheless, devoted as much research and attention to the problems of college students as they have to those of high schools' students [30]. In fact, recent research on youth in North America and Europe has shown the relationship among socio-demographic variables on psychological wellbeing of university and high school students. However, little attention is given in research about the contribution of school support, teacher support and peer (friend) support to the lives of college students in particular.

In Ethiopia, research on university students was mainly limited to examining the problems of youth $[31,32]$. Cases in point are stress and academic performance [33], adjustment Problems [34,35] and associated factors, mental distress of undergraduate [36] medical Students [35,37], substance use and risky sexual behavior [38], 'chat' chewing habit and its interdependence with alcohol drinking [39], and commercial sex work of female students [40]. None of the previous studies in Ethiopia had attempted to examine the role of instructors' support, university support and peer group support in promoting psychological wellbeing of college students. In an attempt to fill in this gap, this research is intended to examine psychological wellbeing as a function of instructors' support, university support and peer group support in the Amhara Regional Universities the following questions as a guide:

- What is/are the level of psychological wellbeing (total and components) of the students in Amhara regional universities?

- Is there a statistically significant difference between groups of students (male-female, parental income level, grade level) in psychological wellbeing?

- What is the perceived level of university support, instructors support and peers' support?

- What is/are the independent contribution of university support, instructors' support and peer's (friend's) support in predicting psychological wellbeing (total and components)?

\section{Methods}

\section{Research design}

Explanatory, cross-sectional, quantitative design was used to collect, analyze, and interpret data. The rationale behind using this design is basically that the major purpose is to examine patterns of psychological well-being among young people operating under stressful conditions, and determine the extent to which university support, instructor support as well as the widely acclaimed peer support would buffer vulnerability to illness.

\section{Participants}

The study is conducted in universities found in the Amhara National Regional State. There are seven universities in this region. From these universities, Bahir Dar University, Wollo University, and Debre Tabor University were taken as a sample. Stratified random sampling was used to select both the three universities as well as participants. Initially, the seven universities were stratified by year of establishment or conveniently called "generation". In terms of year of establishment, universities in Ethiopia so far are known to belong to three generations (first, second, and third). Accordingly, while Bahir Dar University was randomly selected from first generation, Wollo University was selected from the Second generation and Debre Tabor from the new (third) generation universities. The population of the study consisted of the regular students in these three universities that constituted a total of 21,304 (Table 1) students based on information obtained from 
Registrars' offices in the respective universities. After selecting the universities, the next step was to fix on the sample size to be employed as data sources. Hence, applying Naing et al. [41] formula, a sample size of 384 (males=217, females=167) participants were selected following the stratified variant of probability sampling techniques. The procedure was such that the universities were stratified by grade level and then further by gender. A random sample was then selected from all those strata created at last based on the technique of proportional allocation.

\section{Instruments}

The data collection tool used for this study is a questionnaire comprised of five sets of categories: demographic characteristics, psychological well-being measures, university support scale, instructors/teacher support scale, and friend (peer) support scale.

Psychological well-being measures: The psychological well-being scale, originally designed by Ryff [5], was adopted and utilized to measure college students' wellbeing. The scale is a self-report instrument that measures autonomy (self-determination, independence, and the regulation of behavior from within), environmental mastery (ability to choose or create environments suitable to one's strengths so defined as a characteristic of mental health), personal growth (desire for continual development of one's potential, to grow and expand as a person), positive relations with others (sense of warm, trusting, loving, and interpersonal relationships), purpose in life (a sense of directedness, and intentionality) and self-acceptance (defined as characteristic of Maslow self-actualization, Rogers' optimal functioning, Allport's maturity and life span theories acceptance of one's past life). The psychological well-being is then composed of six sub scales each composed of 9 items; hence a total of 54 items. Respondents are expected to self-rate against each item on six scale points that range from a minimum of 1 to a maximum of 6; ' 1 ' indicating lower and ' 6 ' indicating higher psychological well-being. Based on the scoring norms of the subscales, the cuts off scores classify participants in to three status groups: low (9-26 score), moderate (27-35 score) and high (36-54) and, hence, summing up the six sub scales the cut of score for the total scale is low (54-156), moderate (157-210), and high (211-324) [5].

Ryff [5] scale of Psychological well-being is a valid and reliable measure of psychological well-being. It can aid colleges and universities in understanding the degree to which their students are self-accepting, are pursuing meaningful goals with a sense of purpose in life, have established quality ties with others, are autonomous in thought and action, have the ability to manage complex environments to suit personal needs and values, and continue to grow and develop. The test retest reliability of the sub scales range from 0.81 to 0.85 and the internal consistency ranged from 0.87 to 0.90 (Table 2).

University inventory scale: This sub scale was designed to measure students' perceptions of whether their college is enabling their psychological well-being using seven items. Originally developed by Peterson [42], the scale consisted of eight items that describe characteristics that enhance students' psychological well-being. A four

\begin{tabular}{|c|c|c|c|c|c|c|c|}
\hline \multicolumn{2}{|c|}{ Universities } & \multicolumn{3}{|c|}{ Population } & \multicolumn{3}{|c|}{ Sample } \\
\hline & & Male & Female & Total & Male & Female & Total \\
\hline & Bahir Dar & 10521 & 4645 & 15166 & 108 & 85 & 193 \\
\hline & Wollo & 2685 & 1909 & 4594 & 79 & 55 & 134 \\
\hline \multicolumn{2}{|c|}{ Debre Tabor } & 1053 & 491 & 1544 & 30 & 27 & 57 \\
\hline \multirow[b]{2}{*}{ Total } & Population & 14259 & 7045 & 21304 & & & \\
\hline & Sample & & & & 217 & 167 & 384 \\
\hline
\end{tabular}

Table 1: Population and sample of the research participants.

\begin{tabular}{|c|c|c|c|c|}
\hline Sub-Scales & $\begin{array}{c}\text { Number } \\
\text { of items }\end{array}$ & $\begin{array}{c}\text { Previous } \\
\text { study }\end{array}$ & Pilot study & $\begin{array}{c}\text { present } \\
\text { (main) study }\end{array}$ \\
\hline Autonomy & 9 & 0.86 & 0.72 & 0.75 \\
\hline Self-acceptance & 9 & 0.93 & 0.73 & 0.81 \\
\hline $\begin{array}{c}\text { Positive Relations with } \\
\text { others }\end{array}$ & 9 & 0.91 & 0.79 & 0.82 \\
\hline Environmental Mastery & 9 & 0.90 & 0.70 & 0.87 \\
\hline Purpose in Life & 9 & 0.90 & 0.80 & 0.84 \\
\hline Personal Growth & 9 & 0.87 & 0.84 & 0.90 \\
\hline $\begin{array}{c}\text { Psychological well- } \\
\text { being total }\end{array}$ & 54 & 0.93 & 0.87 & 0.96 \\
\hline University Support & 8 & 0.76 & 0.71 & 0.79 \\
\hline Instructors' support & 7 & 0.78 & 0.74 & 0.80 \\
\hline Peer group support & 10 & 0.77 & 0.79 & 0.87 \\
\hline
\end{tabular}

Table 2: Cronbach's alpha coefficients of the well-being, Instructor support and peer support scales in the original $(\mathrm{N}=2456)$, the pilot study $(\mathrm{N}=40)$ and the present final sample $(\mathrm{N}=384)$.

point Likert-type was used with scale points ranging from 1 to 4 (not at all true $=1$ point, a little true $=2$ points, pretty much true $=3$ points and very much true $=4$ ). The total score was used to indicate the level of positive perceptions of college support. The Cronbach alpha for reliability of the instrument in current study was 0.78 .

Instructor inventory scale: Originally developed by Peterson [42], this Likert-type scale consisted of seven items to be rated on a five point options ranging from 1 (strongly disagree) to 5 (strongly agree). It was designed to measure students' perceptions of whether their instructors are enabling their psychological well-being. Higher scores reflect a more positive perception that the instructors are enabling their psychological well-being. The total score was used to indicate levels of positive perceptions of instructors' support. The Cronbach alpha reliability of the instrument in current study was 0.78 .

Peer support scale: Peer group support scale is a sub scale of the social support measure for children and adolescent as well as youth [43]. This sub scale contains ten (10) items which require participants to rate on a five point scale ( 1 or never to 5 or always) the extent to which the support received from peers was important, enabling, and relevant.

\section{Procedures}

As already indicated, the scales of measurement were all adapted from previous versions. A lengthy procedure of adaptation was followed to ensure the validity and reliability of these scales. Firstly, attempts were made to check the (face and content) validity and cultural sensitivity (content and language appropriateness) of the sub scales by the researchers themselves. Having cleared this concern, the second step was then (backward and forward) language translation. Initially, the scales were in English language and then they were translated into Amharic by a language expert having long years of experience in translation. Another language instructor translated the English version into Amharic and one $\mathrm{PhD}$ psychology instructor and the first Language instructor translated it back from Amharic to English language. Some differences that appeared in the forward and backward translations were corrected by the translators jointly with the researchers. The final Amharic version of the scales was given for one Amharic senior instructor to evaluate the contextual meaning of the wordings used in relation with the study context. Following the translation, the Amharic version was tried out with a sample of 40 participants to check the clarity of items, appropriateness of the number of scale points, procedure of administration, and reliability of the scales. The feedback from the field was incorporated, reliability indices were 
established and final versions were prepared. Reliability indices of the original, pilot-tested, and final versions of the sub scales are presented in Table 2. According to Bryma and Bell [44], the Cronbach's Alpha result of 0.7 and above implies acceptable level of internal reliability. Therefore, the pilot test results in the above indicate that all scales are acceptable to conduct research in our locality.

\section{Results}

\section{Demographic characteristics of respondents}

Table 3 shows the sex composition, age structure, year in college and monthly income of students' families in the study. As it can be noted in Table 3, while the mean age of participants is 22.43 years and the mean monthly income of parents is Birr 1780.36. Of course, it can also be seen in this table that all the university grade levels were represented more or less proportionally.

\section{Psychological well-being of university students}

In an attempt to see the status of psychological well-being students, total scores of participants were categorized into the three levels based on the norm of scaling the scores indicated in the instrument. This norming of scores is employed to determine the status of psychological well-being. As shown in Table 4, almost 98.4 percent of the respondents scored moderate and high on autonomy dimension. In a comparable manner, about $91.9 \%$ of the participants had moderate and above score in positive relation with others. The majority $254(66.1 \%)$ of participants still scored moderate and above on personal growth. On the contrary, nearly half of the participants seem to have low environmental mastery (or ability to choose or create environments suitable to his or her strengths and the ability to control complex environments), purpose in life (vision or clear comprehension of life's purpose, a sense of directedness, and were not being productive and creative or were with poor psychological wellness), and self-acceptance. Along with this divided distribution, it was found that nearly comparable proportion of participants are with low and moderate to above total psychological well-being score.

\begin{tabular}{|c|c|c|c|c|c|}
\hline \multirow{2}{*}{\multicolumn{2}{|c|}{ Respondents Characteristics }} & \multicolumn{2}{|c|}{ Sex } & \multicolumn{2}{|c|}{ Total } \\
\hline & & \multirow{2}{*}{$\begin{array}{c}\text { Male } \\
197\end{array}$} & \multirow{2}{*}{$\begin{array}{c}\text { Female } \\
145\end{array}$} & \multirow{2}{*}{$\begin{array}{c}\text { Freq. } \\
342\end{array}$} & \multirow{2}{*}{$\begin{array}{c}\% \\
89 \%\end{array}$} \\
\hline & $18-25=21.5=7353$ & & & & \\
\hline$($ Mean=22.43) & $26-34=30=1260$ & 20 & 22 & 42 & $11 \%$ \\
\hline \multirow{3}{*}{ Year (Batch) } & Freshman( $\left(1^{\text {st }}\right.$ year $)$ & 89 & 60 & 149 & $38.8 \%$ \\
\hline & Sophomore ( $2^{\text {nd }}$ year $)$ & 52 & 47 & 99 & $25.8 \%$ \\
\hline & Senior (>2 $>$ nd $y e a r)$ & 76 & 60 & 136 & $35.4 \%$ \\
\hline \multirow{4}{*}{$\begin{array}{c}\text { Family } \\
\text { monthly } \\
\text { income } \\
\text { (Birr 1780.36) }\end{array}$} & below 1000 & 51 & 62 & 113 & $29.4 \%$ \\
\hline & $1001-2000$ & 88 & 43 & 131 & $34.1 \%$ \\
\hline & $2001-3000$ & 52 & 40 & 92 & $24 \%$ \\
\hline & 3001 and above & 26 & 22 & 48 & $12.5 \%$ \\
\hline
\end{tabular}

Table 3: Background characteristics of participants.

\begin{tabular}{|c|c|c|c|c|c|c|}
\hline \multirow{2}{*}{ Variables } & \multicolumn{2}{|c|}{ Low (9-26 ) } & \multicolumn{3}{c|}{ Moderate(27-35) } & \multicolumn{2}{c|}{ High (36-54) } \\
\cline { 2 - 7 } & Freq. & \% & Freq. & \% & Freq. & \% \\
\hline Autonomy & 6 & 1.6 & 168 & 43.7 & 210 & 54.7 \\
\hline Positive Relation with others & 31 & 8.1 & 133 & 34.6 & 220 & 57.3 \\
\hline Environmental Mastery & 221 & 57.5 & 103 & 26.8 & 60 & 15.6 \\
\hline Personal Growth & 130 & 33.8 & 129 & 33.6 & 125 & 32.5 \\
\hline Purpose in Life & 210 & 54.7 & 64 & 16.7 & 110 & 28.6 \\
\hline Self-Acceptance & 196 & 51 & 165 & 43 & 23 & 6 \\
\hline $\begin{array}{c}\text { Psychological well-being } \\
\text { total }\end{array}$ & 192 & 50 & 134 & 35 & 37 & 15.1 \\
\hline
\end{tabular}

Table 4: Summary results of status of sub dimension of psychological wellbeing of students $(\mathrm{N}=384)$.

\section{Level of perceived support}

University students' perceived level of support from each part is summarized on Table 5. As indicated in the table, students report to get better support from teachers followed by university support. But, it is surprising that perceived peer support is much lower than both groups as well as the expected level of support.

\section{Group differences in psychological well-being}

One of the basic questions of the study is to check whether there exists association between background variables (sex, family monthly income and year (batch) and psychological well-being. To examine the relationship between predictors and outcome variables, Pearson product moment correlation was used (Table 6). Table 6 shows that while batch of students has no significant relationship with all variables, sex and income are correlated significantly with almost all the psychological well-being measures. Sex has significant negative relationship with autonomy $(r=-0.287, p<0.01)$, environmental mastery $(r=-0.240$, $\mathrm{p}<0.01)$, personal growth $(\mathrm{r}=-0.201, \mathrm{p}<0.01)$, purpose in life $(\mathrm{r}=-$ $0.238, \mathrm{p}<0.01)$, self- acceptance $(\mathrm{r}=-0.251, \mathrm{p}<0.01)$ and Psychological Well-being Total $(\mathrm{r}=-0.181, \mathrm{p}<0.05)$; and positively correlated with positive relation with others $(\mathrm{r}=0.193, \mathrm{p}<0.01)$. Family income was significantly and positively correlated with autonomy $(\mathrm{r}=0.154, \mathrm{p}<0.01)$, environmental mastery $(\mathrm{r}=0.171, \mathrm{p}<0.01)$, personal growth $(\mathrm{r}=0.193$, $\mathrm{p}<0.01)$, purpose in life $(\mathrm{r}=0.169, \mathrm{p}<0.01)$, self- acceptance $(\mathrm{r}=0.120$, $\mathrm{p}<0.05)$, and psychological well-being total $(\mathrm{r}=0.161, \mathrm{p}<0.01)$. Because the intercorrelation between the background factors was almost insignificant, there is no need for conducting further analysis to partial out overlaps and then determine net effect of these predictor variables. We would say that both sex and income make significant independent contributions to predicting well-being.

\section{Independent (predictor) variables}

Person product moment correlations ( $r$ ) were computed to find out whether there was a significant relationships among variables treated in the study or not. The results are presented in Table 7. Table 7 shows that college support has significant positive relationship with teacher support $(\mathrm{r}=0.129, \mathrm{p}<0.05)$, and Peer (friend) support $(\mathrm{r}=0.162, \mathrm{p}<0.01)$. Teacher support is not significantly correlated with peer (friend) support ( $\mathrm{r}=0.094)$.

\section{Prediction of psychological well-being by the predictors}

The correlation among the predictor variables selected for predicting well-being needs to be partialed out to check the independent contribution of each predictors 'partial out or step wise regression is used for this purpose. However, the inter-correlation between predictors are noted should not be strong enough to violate the multicollinearity (or collinearity) assumption needed to apply the stepwise regression analysis to determine the independent contribution of predictors. In fact, the inter-predictor correlation is not strong enough to violate this assumption and hence we proceed with application of the stepwise regression analysis. Table 8 presents the model summary of these regression analyses separately for each dimension of wellbeing.

The first multiple regression analysis yielded that peer and instructors' support together accounted for $45 \%$ of the variance on students' autonomy. In the same way, the independent contribution of peer (friend) and instructors' support is significant each accounting for $43.8 \%$ and $1.1 \%$ of the total variance respectively. Regarding environmental mastery, peer group support was found to be the variable that relatively accounted for the highest variation in students' environmental mastery. This variable explained $46 \%$ of the total 
Citation: Kibret BT, Tareke G (2017) The Contribution of Instructor, Peer and University Support for Promoting Psychological Well-Being among Students in the Amhara Regional Universities. Clin Exp Psychol 3: 154. doi: 10.4172/2471-2701.1000154

Page 5 of 8

\begin{tabular}{|c|c|c|c|c|c|c|}
\hline Variables & $\begin{array}{c}\text { Number of } \\
\text { items }\end{array}$ & Scale points & Expected mean & Min & Max & Mean \\
\hline University Support & 8 & 4 & 20 & 2.00 & 36.00 & 18.2344 \\
\hline Teachers Support & 7 & 5 & 21 & 10.00 & 50.00 & 32.7734 \\
\hline Peer(Friend) Support & 10 & 5 & 30 & 7.00 & 40.00 & 23.7344 \\
\hline
\end{tabular}

Table 5: Mean and standard deviations, minimum, and maximum of psychological well-being and contextual factors $(\mathrm{N}=384)$.

\begin{tabular}{|c|c|c|c|c|c|c|c|c|c|}
\hline Sex $(=1$, Male $=2$, female $)$ & 1 & & & & & & & & \\
\hline Batch (2) & 0.035 & 1 & & & & & & & \\
\hline Family income (3) & -0.056 & -0.004 & 1 & & & & & & \\
\hline Autonomy (4) & $-0.287^{* *}$ & 0.034 & $0.154^{* *}$ & 1 & & & & & \\
\hline Positive relation (5) & $0.193^{* *}$ & 0.01 & 0.068 & $0.491^{* *}$ & 1 & & & & \\
\hline Environmental Mastery (6) & $-0.240^{* *}$ & 0.032 & $0.171^{* *}$ & $0.880^{* *}$ & $0.494^{* *}$ & 1 & & & \\
\hline Personal Growth (7) & $-0.201^{* *}$ & 0.056 & $0.198^{* *}$ & $0.883^{* *}$ & $0.486^{\star *}$ & $0.968^{* *}$ & 1 & & \\
\hline Purpose in Life & $-0.238^{* *}$ & 0.083 & $0.169^{\star *}$ & $0.892^{* *}$ & $0.529^{* *}$ & $0.946^{\star *}$ & $0.965^{\star *}$ & 1 & \\
\hline Self- acceptance & $-0.251^{* *}$ & 0.082 & $0.120^{*}$ & $0.882^{\star *}$ & $0.613^{\star *}$ & $0.886^{\star *}$ & $0.877^{\star *}$ & $0.954^{\star *}$ & 1 \\
\hline Psychological well-being total (10) & $-0.181^{* *}$ & 0.052 & $0.161^{* *}$ & $0.919^{* *}$ & $0.673^{* *}$ & $0.951^{* *}$ & $0.954^{* *}$ & $0.973^{* *}$ & $0.958^{* *}$ \\
\hline
\end{tabular}

Table 6: Correlations between subscales of the Psychological well-being and background factors $(\mathrm{N}=384)$.

\begin{tabular}{|c|c|c|}
\hline & College Support & Instructors' Support \\
\hline College Support & 1 & $0.129^{*}$ \\
\hline Instructors' Support & $0.162^{* *}$ & 1 \\
\hline Peer(friend) support & 0.094 \\
\hline
\end{tabular}

Table 7: Pearson product moment correlation matrix of contextual variables $(\mathrm{N}=384)$.

\begin{tabular}{|c|c|c|c|c|c|c|c|c|}
\hline variables & steps & Variables Entered & $\mathbf{R}$ & $\mathbf{R}^{2}$ & Adjusted $\mathbf{R}^{2}$ & $\mathbf{R}^{2}$ Change & F Change & $\begin{array}{c}\text { Sig. F } \\
\text { Change }\end{array}$ \\
\hline \multirow{2}{*}{ Autonomy } & 1 & Peer Group support & 0.662 & 0.438 & 0.437 & 0.438 & 297.872 & 0.001 \\
\hline & 2 & Instructors support & 0.670 & 0.450 & 0.447 & 0.011 & 7.889 & 0.005 \\
\hline \multirow{2}{*}{$\begin{array}{c}\text { Environmental } \\
\text { mastery }\end{array}$} & 1 & Peer support & 0.679 & 0.460 & 0.459 & 0.460 & 325.968 & 0.000 \\
\hline & 2 & Teacher support & 0.683 & 0.467 & 0.464 & 0.006 & 4.437 & 0.036 \\
\hline \multirow{2}{*}{ Positive relation } & 1 & Peer support & 0.372 & 0.138 & 0.138 & 61.380 & 263.604 & 0.001 \\
\hline & 2 & Teacher support & 0.391 & 0.154 & .014 & 6.496 & 35.592 & 0.001 \\
\hline \multirow{2}{*}{ Personal growth } & 1. & Peer support & 0.736 & 0.542 & 0.541 & 0.542 & 452.454 & 0.000 \\
\hline & 2. & Teacher support & 0.742 & 0.550 & 0.548 & 0.008 & 6.747 & 0.010 \\
\hline \multirow{3}{*}{ self-acceptance } & 1 & Peer group Support & 0.614 & 0.377 & 0.375 & 0.377 & 230.744 & 0.000 \\
\hline & 2 & Instructors Support & 0.619 & 0.384 & 0.380 & 0.007 & 4.333 & 0.038 \\
\hline & 3 & University Support & 0.624 & 0.390 & 0.385 & 0.006 & 3.888 & 0.049 \\
\hline \multirow{2}{*}{ Purpose in life } & 1 & Peer support & 0.694 & 0.482 & 0.481 & 0.482 & 355.455 & 0.000 \\
\hline & 2 & Instructors support & 0.700 & 0.490 & 0.487 & 0.008 & 5.732 & 0.017 \\
\hline \multirow{2}{*}{$\begin{array}{l}\text { Psychological } \\
\text { wellbeing }\end{array}$} & 1 & Peer support & 0.691 & 0.478 & 0.477 & 0.478 & 349.968 & 0.000 \\
\hline & 2 & Instructors support & 0.697 & 0.486 & 0.483 & 0.007 & 5.498 & 0.020 \\
\hline
\end{tabular}

Table 8: Model summary of stepwise regression of by college support, instructors, support and peer (friend) support ( $n=384$ ).

variance in environmental mastery. This was statistically significant $(\mathrm{F} 1,382=325.968, \mathrm{P}<0.001)$. Instructors support was the next predictor that was entered to the regression equation. Its inclusion raised the coefficient of determination by $0.6 \%$, which is a statistically significant increase $(\mathrm{F} 1=4.437, \mathrm{P}<0.05)$. As compared to instructors support, peer (friend) support contributed more to the variation in environmental mastery. The contribution of the University support was not significant. This implies that students control their environment by the help of their peers (friends).
The total explained variance in 'positive relation with others' (15.3\%) has come from an independent contribution of peer (13.8\%) and instructors' (1.4\%). Of course, the independent contribution of peer (friend) support is the highest contribution to the variance of the students' positive relation with others. Peer (friend) support was found to be the variable that accounted for the highest variation in students' personal growth. This variable explained $54.2 \%$ of the variability in personal growth. This was statistically significant $(\mathrm{F} 1=452.454, \mathrm{P}<0.001)$. Instructors support was the next best predictor 
that was entered into the regression equation. Its inclusion increased the coefficient of determination by $0.8 \%$. The increase in $\mathrm{R} 2$ was statistically significant $(\mathrm{F}=6.747, \mathrm{P}<0.05)$. Moreover, peer (friend) support alone could explain $37.5 \%$ of the variance in self-acceptance. This was statistically significant $(\mathrm{F} 1=230.744, \mathrm{P}<0.001)$. The next best predictor identified in the analysis was instructors support. Its inclusion into the regression equation raised the coefficient of determination by $0.7 \%$. This increase was statistically significant $(\mathrm{F} 2=4.333, \mathrm{P}<0.05)$. The independent contribution of university support was $0.6 \%$, which was significant $(\mathrm{F}=3.888, \mathrm{P}<0.05)$. Compared to instructors support, and University Support, peer group accounted for more variation in selfacceptance.

The regression analyses results also indicated that the composite contribution of, peer (friend) support, and instructors support to the variance of the students purpose in life was $49 \%$. This indicated that $51 \%$ of the variance on the students' purpose in life was contributed by other factors that were not included in the present study. In the regression model of the same table, $\mathrm{R} 2$ change reveals information on the variance in psychological wellbeing explained by each of the three of variables. The independent contribution of peer (friend) support, and teacher support to students purpose in life were $48.2 \%$, and $0.8 \%$ respectively, which was significant $(\mathrm{F}=355.455, \mathrm{P}<0.001$; and $\mathrm{F}=5.732$, $\mathrm{P}<0.05$ respectively). However, University support was excluded by step wise regression, because of insignificant contribution to students meaning and purpose in life. Finally, the independent contribution of peer (friend) support, and Instructors support accounted for $47.8 \%$ and $0.7 \%$ of the variance to students Psychological Well-being total respectively. This means the joint contribution of peer (friend) support, and teacher support was $48.6 \%$. Of these, contributions of Peer (friend) support had the highest contribution to the variance of the students psychological well-being total.

\section{Discussion}

The objectives of this study were to assess the status of university students' psychological well-being, compare this status by gender, batch and family income, and examine the extent to which perceived university, teacher and peer (friend) support contribute to the total explained variance in psychological well-being scores.

The findings have generally suggested that except for autonomy and 'positive relation with others', university students' general psychological wellbeing (total well-being) and three other basic areas of functioning (environmental mastery, purpose in life, and self- acceptance) are worrisome as it was also partly supported by previous research that college and high school students tend to show lower score on purpose in life and personal growth [45-51]. Of course, it was noted that girls as well as those with lower parental monthly income were found to be more vulnerable lower psychological wellbeing than boys and those with better monthly parental income. In fact, freshman students were not that different from others contrary to many research findings in Ethiopia that these students are vulnerable as a group than others.

Like many other western higher education, pursuing university education in Ethiopia appears to be stressful and would generate different problems of not only an academic nature but even more importantly a psychological ones. According to Yusuf [52] students continuing higher education encounter 'all kinds of problems', while economic, psychosocial, educational, and health are among the dominant concerns. Freshman students are even the ones to suffer from either multiple or at least one form of the commonly reported problems more frequently than seniors [52].
Relatively recent studies conducted in Ethiopian higher institutions on prevalence of adjustment problems [34,35], mental distress [36,53], and psychological and social hazards of a serious nature that require (professional) intervention on top of help rendered by friends and relatives [39]. For example, Almaz [35] studied prevalence and associated factors of adjustment problems among St. Paul's Hospital first year Millennium Medical College students using Students' found that $37.8 \%$ of the respondents had adjustment problems: difficulty adjusting to college class and work load, living arrangement (dormitory) and managing time and study skill. Jemal [34] explored Jimma university freshman students with the purpose of exploring the level and correlates of adjustment problems also showed that half (50\%) of freshman students were experienced social adjustment problems than educational and personal psychological. The study also revealed that female students are more prone to all forms of such adjustment difficulties, particularly of social adjustment difficulties as compared to their male counterparts. Ayele explored freshman students' adjustment problems in Assela College of Teachers' Education and revealed that freshman college students experience personal and emotional, environmental, academic and instructor-related dimensions of adjustment problems and in his study female students experience adjustment problems more than male students [54]. Similarly, other local studies revealed that Ethiopian colleges, particularly the freshmen, encounter enormous

Other studies prevalence show that mental distress accounts 19.3\% [53] and 49.1\% [36] with exclusion and inclusion of freshmen students respectively. A study in Hawasa University indicated that there was high prevalence of mental distress among first year students when compared to other students in (self-reporting questionnaire [36]. Abebayehu [36] affirms that first year dropouts in Ethiopian higher learning institutions have reached 10 to 15 per cent. It is often associated with "difficulty in adjusting to campus life away from home" [55].

Although the participants experience difficulties in psychological wellbeing, the support services put in place would seem to hardly contribute to students' resilience as they are perceived to be much lower. Yet, they are important predictor variables explaining variance in wellbeing scores except for peer support. In fact, this stands in tune with many research findings already presented in the introduction section as well as established practices in Ethiopian universities about the use of peer learning possibly despite the fact that the practice has been highly politicized thus generating a feeling resentment among the students.

The second predictor of this study was instructors support. Similarly, the student -teacher relationship is a critical aspect of the school environment, with studies demonstrating that student perception of positive relations with teachers and other school staff contribute to improved social and emotional functioning over time. Moreover, supportive student -teacher relationships are linked to beneficial social-emotional out comes (positive peer relations as well as decreases in suicidal ideations, externalizing behaviors, emotional distress, violence, substance abuse, and sexual activity) and enhance psychological wellness of students.

Finally, there were contradictory results with regard to University support and students' psychological well-being found in this study and those in the literature already summarized in the literature. In this study, University support has insignificant contribution on students' psychological wellbeing. University support system in Ethiopian higher institutions today does not seem well developed to addressing particularly the psychosocial needs of students. Of course, there are many services and support programs but basically confined to enhancing academic needs [56-58]. 
Citation: Kibret BT, Tareke G (2017) The Contribution of Instructor, Peer and University Support for Promoting Psychological Well-Being among Students in the Amhara Regional Universities. Clin Exp Psychol 3: 154. doi: 10.4172/2471-2701.1000154

\section{Conclusion}

- General psychological wellbeing, environmental mastery, purpose in life, and self-acceptance are lower among university students compared to autonomy, personal growth, and relationship with others.

- Girls and those from lower family income group are more vulnerable than their counterparts compared to grade level in which little difference was noted in psychological well-being and grade level.

- Perceived university support, teacher support, and peer support were lower.

- However, peer support and teacher support were significant predictors of psychological well-being compared to university support that proved to be less useful.

\section{Recommendations}

Based on the major findings and conclusions made, the following possible solutions which can enhance the psychological well-being of students' were recommended:

- University support is one of the most important resources for students psychological well-being. However, this study indicated that University support contributed insignificantly to the variance in psychological well-being. Therefore, the university context need to be changed and improved to meet students' needs and foster students' psychological well-being. More attention needs to be paid to instituting special support services to girls. Arranging part-time job for children from lower parental monthly income is important.

- For students to increase their level of psychological well-being, they need to develop positive attitude towards themselves and their learning, involve themselves in activities and make a habit of noticing the good things in their lives. Providing integrative and continuous life skill training might play a pivotal role to enhance students' psychological health.

- Further investigation is needed to determine why grade level turned out to be insignificantly correlated with wellbeing unlike almost all previous research in Ethiopia showing that first year students were more vulnerable to mental distress, adjustment problems and psychological health.

\section{References}

1. Zwerling LS, London HB (1992) First-generation students (New Directions for Community Colleges Series, No. 80). Jossey-Bass, San Francisco.

2. Tinto $\vee(1993)$ Leaving college : Rethink the causes and cures of student attrition.

3. Dzuka J, Dalbert C (2000) Well-being as a psychological indicator of health in old age: A Erlbaum. Research agenda. Studia Psychologica 42: 61-70.

4. Deci EL, Ryan RM (2008) Hedonia, eudaimonia, and well-being: An introduction. Journal of Happiness Studies 9: 1-11.

5. Ryff CD (1995) The structure of psychological well-being revisited. J Pers Soc Psychol 69: 719-727.

6. Ryan RM, Deci EL (2001) On happiness and human potentials: A review of research on hedonic and eudaimonic well-being. Annu Rev Psychol 52: 141166

7. Jorgensen IS, Nafstad HE (2004) Positive psychology: Historical, philosophical and epistemological perspectives.

8. Bretherton R, Orner RJ (2004) Positive psychology and psychotherapy: An Existential approach.

9. Diener E (2000) Subjective well-being: The science of happiness and a proposal for a national index. American Psychologist 55: 34-43.

10. Garmezy N (1985) Stress resistant children: The search for protective factors. In: Stevenson JE (ed.). Recent Research in developmental psychopathology. Pergamon Press, Oxford, England. pp: 213-233.

11. Harris A, Thoreson C (2003) Strength-based health psychology: Counseling for total human health. In: Counseling psychology and optimal human functioning. Lawrence Erlbaum Associate Publishers, Mahwah, NJ.
12. Bokhorst CL, Sumter SR, Westenberg PM (2009) Social support from parents friends, classmates, and teachers in children and adolescents aged 9 to 18 years: Who is perceived as most supportive? Social Development Research 2: $1-10$.

13. Suldo E (2009) Teacher support and adolescents subjective well-being. A mixed method investigation. School psychology review 1: 67-85.

14. Schonert-Reichi KA (2010) Our children's voices: The middle year's development instrument. Measuring the developmental health and wellbeing of children.

15. Felner RD (2000) Educational reform as ecologically-based prevention and promotion: The project on high performance learning communities.

16. Felner R, Felner T, Silverman M (2000) Prevention in mental health and socia intervention: Conceptual and methodological issues in the evolution of science and practice of prevention.

17. Hunter L, Elias MJ (1998) Violence in the high schools: Issues, controversies, and policies, and prevention programs.

18. Oberle E, Schonert-Reichl KA, Zumbo BD (2010) Life satisfaction in early adolescence: Personal, neighborhood, school, family, and peer influences. Journal of Youth and Adolescence.

19. Joronen K (2005) Adolescents' subjective well-being in their social contexts. Academic dissertation, university of Tampere, Finland.

20. Ahonen A, Rijala R (2006) Psychosocial well-being among school children in the Northern areas of Finland, Sweden, Norway and North-west Russia. Arctichildren research and development findings from northern areas of Finland, Sweden, Norway and north-west Russia Rovaniem. University of Lapland, Finland.

21. Savig L, Schwartz SH (2000) Values priorities and subjective well-being: Direct relations and congruity effects. Eur J Soc Psychol 30: 177-198.

22. Shochet IM, Smyth T, Homel R (2007) The impact of parental attachment on Adolescents Perception of the school environment and school connectedness. Anzjft 28: 109-118.

23. Kiuru N (2008) The role of adolescents peer group in the school context Studies in Education Psychology and Social Research 333: 1-80.

24. Noona K, Nurmi J, Aunola K, Salmela-Aro K (2008) Peer group influence and selection in adolescents' school burn out: a Longitudinal study (Report). Medicine and health psychology and mental health.

25. Lerner RD, Weiner IB, Easterbrooks MA, Mistry J (2003) Hand book of psychology: Developmental psychology. Johnwiley and Sons, Inc., New Jersey.

26. Saric ZR, Zganec AB, Sakic M (2008) Life satisfaction in adolescences: The effect of perceived family economic status, self-esteem and quality of family and peer relationship. Primljeno 4: 547-561.

27. Basson N (2008) The influence of psycho social factors on the subjective wellbeing of adolescents. Doctoral dissertation, Bloemfontein, Free State University.

28. Colemon B, Holder MD (2007) The contribution of social relationships to children's happiness. Journal of Happiness Study 10: 329-349.

29. Aksum University (2012) Introducing and institutionalizing peer learning among students in Aksum University: Motives and modalities. Aksum University, Zero Draft.

30. Cox HG (1988) Later life: The realities of aging (2nd edn.). Prentice-Hall, Inc. New Jersey.

31. Tefera B, Dessie Y (2015) Exploring youth development in Addis Ababa: An alternative strength-based perspective. Ethiopian Journal of Development Research.

32. Tefera B (2008) Notions of fatherhood among adolescents: Nature, effects, and determinants. Gagandeep Publication, Delhi.

33. Tewodros Bekele (2013) The relationship between stress and academic performance of college students: The case of Bonga College of Teacher Education.

34. Jemal G (2006) Adjustment problems of freshman Students at Jimma University, Ethiopia, with Jimma University. Journal of Public Health 1: 9-12.

35. Almaz Seid (2013) Prevalence and factors associated with adjustment problem 
Citation: Kibret BT, Tareke G (2017) The Contribution of Instructor, Peer and University Support for Promoting Psychological Well-Being among Students in the Amhara Regional Universities. Clin Exp Psychol 3: 154. doi: 10.4172/2471-2701.1000154

Page 8 of 8

among first year regular Medical students at Millennium Medical College St. Paulous Hospital. Unpublished MA thesis, Addis Ababa University.

36. Alemayehu A (2009) Prevalence and correlates of mental distress among Regular undergraduate students of Hawassa University: A cross - sectional survey. East African Journal of Public Health 6: 85-94.

37. Atalay A (2005) Mental distress in medical students of Addis Ababa University. PanAfrican Medical Journal.

38. Derese A (2011) Assessment of substance use and risky sexual behavior among Haramaya University Students. Haramaya, Ethiopia.

39. Abdu E (2003) The prevalence of 'chat' chewing habit and its incidental inter dependence with alcohol drinking among AAU, main campus male undergraduate students. The Ethiopian Journal of Development Research 25: 1-51.

40. Messeret Dereje (2013) The new face of the sex industry: Commercial sex work by female students in Addis Ababa and Hawassa Universities: Causes and effects on self esteem. MA Thesis, School of Psychology, Addis Ababa University.

41. Naing L, Winn T, Rusli BN (2006) Practical issues in calculating the sample size for prevalence studies. Archieves of Orofacial Sciences 1: 9-14.

42. Peterson C, Seligman M (2004) Character strengths and virtues: A handbook and classification. American Psychological Association, Washington, DC

43. Malecki CK, Demtray MK (2002) Measuring social support: development of the child and adolescent social support scale (CASSS). Psychology in the School 1: 1-18.

44. Bryman A, Bell E (2003) Business research methods. Oxford University Press Inc., New York.

45. Ryff C, Singer B (1996) Psychological well-being: Meaning, measurement, and implications for psychotherapy Research. Psychother Psychosom 65: 14-23.

46. Ryff C, Singer B (1998) The contours of positive mental health. Psychological Inquiry 9: 1-28
47. Ryff CD (1989) Happiness is everything, or is it? Explorations on the meaning of psychological well-being. J Pers Soc Psychol 57: 1069-1081.

48. Ryff CD (1991) Possible selves in adulthood and old age: A tale of shifting horizons. Psychology and Aging 6: 286-295.

49. Ryff CD, Singer B (1998) Human health: New directions for the next millennium Psychol Inq 9: 69-85.

50. Ryff CD, Keyes CLM, Hughes DL (2003) Status inequalities, perceived discrimination, and eudaimonic wellbeing: Do the challenges of minority life hone purpose and growth? J Health Soc Behav 44: 275-291.

51. Ryff CD, Lee YH, Essex MJ, Schmutte PS (1994) My children and me: Midlife evaluations of grown children and self. Psychology and Aging 9: 195-205.

52. Yusuf O Abdi (1998) Counseling service in institutions of higher education Addis Ababa University, Addis Ababa.

53. Galmessa A (2005) Assessment of prevalence, determinants and effects of mental distress among.

54. Ayele K (2001) Major problems encountered by non-boarding college students: Focus Assela College of Teacher Education Students. The Ethiopian Journal of Education 29: 103-130.

55. William S (2004) Higher education in Ethiopia: The vision and its challenges JHEA/RESA 2: 83-113

56. Diener E (2009) Subjective well-being. A primer for reporters and new comers. University of Illinois.

57. Diener E, Diener RB, Oregon P (2002) Findings on subjective well-being and their implications for empowerment. Psychol Bull 95: 542-575.

58. Seyum G, Ayalew G (1996) Rapid assessment of drug abuse in Ethiopis Narcotics 182: 53-63. 